\title{
Papillary fibroelastomas - 15 years single-centre case series and brief review of the literature
}

\author{
Rina Dalmatin'*, \\ Luka Bastiančič², \\ Teodora Zaninović \\ Jurjević \\ Davorka Žagar ${ }^{3}$, \\ Luka Zaputović \\ Alen Ružić ${ }^{2}$ \\ 'Pula General Hospital, Pula, \\ Croatia \\ ${ }^{2}$ University of Rijeka School of \\ Medicine, University Hospital \\ Centre Rijeka, Rijeka, Croatia \\ ${ }^{3}$ Clinic for Treatment, \\ Rehabilitation and \\ Prevention of Cardiovascular \\ Diseases, Thalassoterapia \\ Opatija, Opatija, Croatia
}

\author{
KEYWORDS: cardiac tumors, cardiac surgery, echocardiography. \\ CITATION: Cardiol Croat. 2017;12(4):152. I https://doi.org/10.15836/ccar2017.152
}

*ADDRESS FOR CORRESPONDENCE: Rina Dalmatin, Opća bolnica Pula, Zagrebačka 30, HR-52100 Pula, Croatia. Phone: +385-98-981-6480 / E-mail: rina.dalmatin@gmail.com

ORCID: Rina Dalmatin, http://orcid.org/0000-0003-1864-3314 • Luka Bastiančić, http://orcid.org/0000-0002-6520-0287 Teodora Zaninović Jurjević, http://orcid.org/0000-0001-8359-3910 • Davorka Žagar, http://orcid.org/0000-0002-0914-6810 Luka Zaputović, http://orcid.org/0000-0001-9415-9618 • Alen Ružić, http://orcid.org/0000-0001-5031-2975 IIIIIIIIIIIIIIIIIIIIIIIIIIIIIIIIIIIIIIIIIIIIIIIIIIIIIIIIIIIIIIIIIIIIIIIIIIIIIIIIIIIIIIIIIIIIIIIIIIIIIIIIIIIIIIIIIIIIIIII Introduction: Cardiac tumors are extremely rare with the incidence $<0.1 \%$, found in approximately 7 of 12.000 autopsies. Papillary fibroelastomas (PFs) are the second most common benign cardiac tumors, peduncular and mobile, typically speckled and echolucent. The mean patient age at detection is 60 years. According to the literature ${ }^{1-3}$, PFs are most commonly seen at the aortic (36\%) and mitral $(29 \%)$ valve, while they can be found on the tricuspid valve in $11 \%$ cases or at the pulmonic valve in $7 \%$ patients. These benign cardiac tumors usually (70 \%) have symptoms and they are mostly due to embolization, either of tumor itself or the tumor associated thrombus.

Methods and Results: From 2002 till today, at the Cardiovascular Department at University Hospital Centre Rijeka, we found 9 cases of PF that have been patohystologically proven. The PFs were most often find at the aortic valve (4 cases), in 2 cases they were situated at the pulmonary valve and the same was the number of PFs found at the mitral valve, while only 1 were found at the tricuspid valve. Only 2 cases were completely asymptomatic, while 7 had symptoms probably related to PF: 4 of them had cerebral embolic symptoms and in 3 cases the coronary embolism was suspected. In only one case the tumor had hemodynamic implications by reducing the effective mitral valve area. In our series, 6 patients with PF were sent to cardiac surgery, and in 3 cases the observation was indicated.

Conclusion: PFs are rare benign cardiac tumors with a high embolic potential. The surgery is reasonable therapeutic option for all patients at risk of embolization or in those with other indications for heart surgery. Nowadays, the PF of the left heart should be considered for operation, while those at the pulmonary and tricuspid valve are removed only in case of surgical revascularization, aortic aneurysm correction or other heart valve disease that is hemodinamically significant. The global PF registry is needed for better understanding of PFs.

\section{RECEIVED:}

March 11, 2017

ACCEPTED:

April 6, 2017

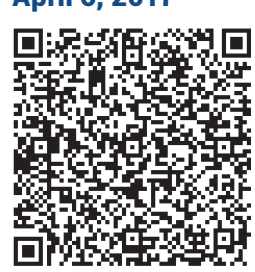

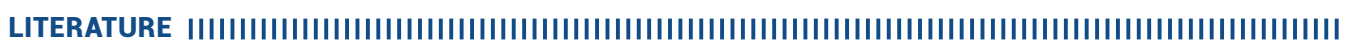

1. Klarich KW, Enriquez-Sarano M, Gura GM, Edwards WD, Tajik AJ, Seward JB. P Papillary fibroelastoma: echocardiographic characteristics for diagnosis and pathologic correlation. J Am Coll Cardiol. 1997 Sep;30(3):784-90. https://doi.org/10.1016/S0735-1097(97)00211-8

2. Boodhwani M, Veinot JP, Hendry PJ. Surgical approach to cardiac papillary fibroelastomas. Can J Cardiol. 2007 Mar 15;23(4):301-2. https://www.ncbi.nlm.nih.gov/pubmed/17380224

3. Gopaldas RR, Atluri PV, Blaustein AS, Bakaeen FG, Huh J, Chu D. Papillary fibroelastoma of the aortic valve: operative approaches upon incidental discovery. Tex Heart Inst J. 2009;36(2):160-3. https://www.ncbi.nlm.nih.gov/pubmed/19436815 